\title{
Some aspects of electroencephalographic disturbances following head injury
}

\author{
ELMAN W. POOLE \\ From the Churchill Hospital, Oxford
}

The aim of this paper is to give a bird's eye view of the electroencephalographic (EEG) disturbances found in patients with head injury, and to indicate the type of information which can come from this investigation. The EEG changes are illustrated wherever possible along with the underlying general principles, since this seemed a more useful approach than to give statistical tables and an elaborate text. An attempt has been made to correlate EEG and clinicopathological findings, and this has necessitated rather formidable illustrations and legends. However it is hoped these will best represent the data to be expected in the necropsy room or clinicopathological conference.

Electroencephalography is concerned with aspects of surviving cerebral function. This may be disturbed in apparently much the same way by varied means, so that accurate prediction of the nature of the underlying lesions is often thought impossible. Knowledge of the clinical situation does much to offset this rather defeatist attitude. However, those anticipating abundant firm pathological confirmation of lesions are bound to be disappointed because many of the patients studied survive. Indeed, early prediction of the reversibility of abnormalities and the quality and likelihood of survival provides the area of greatest challenge and neglect, despite its importance in the allocation of medical resources.

\section{Normal EEG and Types of Abnormality}

A preliminary outline of some normal and abnormal EEG features is necessary. This relates to ordinary routine scalp recordings, but it is worth noting that other kinds of examination are available.
ROUTINEEEGRECOR D

Twenty to 30 minutes of scalp recording in the resting state, with or without hyperventilation or photic stimulation.

\section{SPECIAL E E G RECORD}

(1) Special patient conditions, such as fasting, sleeping, or following a fit (postictal); (2) special recording techniques, such as sphenoidal or depth leads, the averaging of evoked responses (vide infra); (3) polygraph including, for example, respiration, movement, electromyography (EMG).

\section{NORMAL EEG RECORD}

In the waking state, alpha range activity of 8 to 13 cycles per second (cps) is usually present in the postcentral areas; it is fairly symmetrical, tends to disappear (or 'block') with attention such as when the eyes are opened, and it reappears when they are closed (Fig. 1A). There is very little slower activity (theta range 4-7 cps, and delta range $<4 \mathrm{cps}$ ) in the healthy alert adult, but this can be the main activity in children and tends to disappear with aging. The frequency content is fairly constant in the same individual, but it is very susceptible to biochemical changes and the level of consciousness. In Fig. 1B a 3 cps burst appears frontally in response to hyperventilation; and in sleep (Fig. 1C) the normal alpha rhythm has disappeared and the record contains varied symmetrical slow activity and bursts of spindle activity. Such ongoing activity, whether sustained or intermittent, can be called 'spontaneous'. This is in contrast to 'evoked' activity which occurs more strictly in relation to a stimulus; for example, in Fig. $1 \mathrm{C}$ a sound during sleep produces a symmetrical slow wave response (' $\mathrm{K}$ complex'). 
ABNORMAL EEG RECORD

Abnormalities are of two kinds. One consists of 'negative' features, that is, a loss of, or reduction in, the rhythms that would be expected in the particular clinical state. The other consists of 'positive features', that is, the presence of unexpected rhythms for the particular clinical state. Thus in Fig. 1D the normal alpha components, present postcentrally on the left side, are less clearly seen on the damaged right side; there is instead an increase in abnormal mixed slow elements which also appear more anteriorly and are little changed by eye closure. Abnormal rhythms, like normal ones, can be focal or general, sustained or episodic, and can be apparently spontaneous or provoked. All this is vef important in the sampling problems involved for their detection or exclusion. A provoked abnomality is illustrated by the mixed sharp and slozwave burst of epileptic activity following the 17/second flash stimulation shown in Figure 1 $\overline{\mathbf{B}_{\text {. }}}$

The appropriate circumstances may be crucial in demonstrating abnormalities, and sleep 모s particularly useful since it can provide increased repertoire of rhythms for side-to-si and area comparison. Sleep, so to speak, puts the nervous system through more of its paces. This is important because the correlation of defects in several types of activity may provide the bast indication of local disorder even though each of

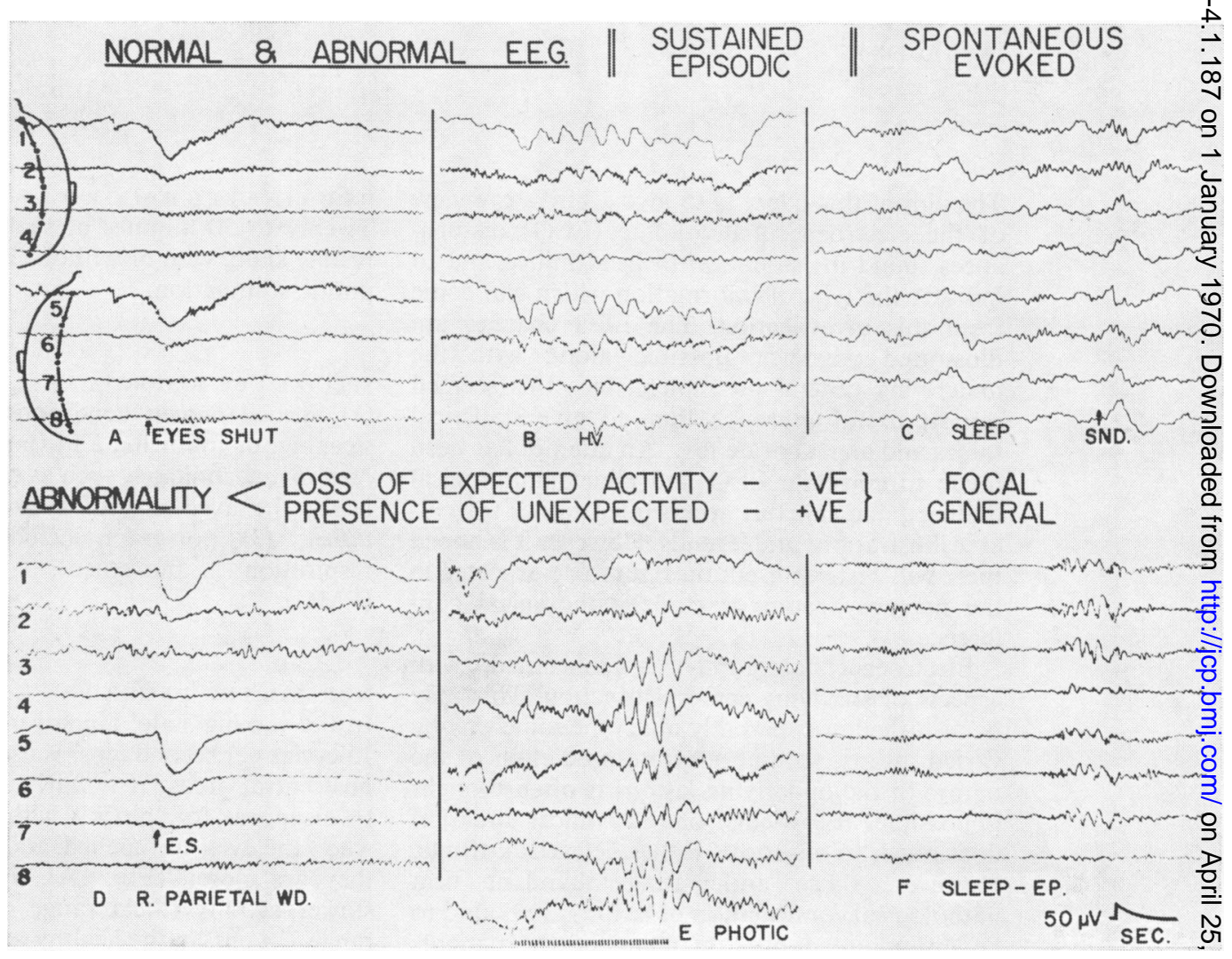

Fig. 1 Normal and abnormal EEG activities Sustained or episodic; and spontaneous or evoked; focal or general.

Normal A Symmetrical alpha activity (11 cps) appearing postcentrally on eye closure in a normal adult. B Biochemical changes-a burst of 2 to $3 \mathrm{cps}$ activity appearing precentrally on hyperventilation in the same individual. C Sleep-bursts of 11 cps sleep spindle activity and slow activity appearing spontaneously in sleep; a non-specific slow wave response is provoked by a sound (' $K$ complex').

Abnormal D Reduction in normal alpha activity posteriorly on the right, and the presence of sustained mixed abnormal irregular slower rhythms in the right parieto-central area. (From a 45-year-old soldier who suffered a right parietal penetrating grenade wound $\mathrm{\omega}$ 20 years earlier, with slight residual sensory and motor deficits and hemianopia.) E Episode of bilateral slow and sharp wave activity provoked postcentrally by photic stimulation at 17 flashes per second. (From as 14-year-old boy who had a massive left subdural hygroma at the age of 7 years following a minor injury at play, and developed occasional fits. Photic-induced disturbances appeared six years after the accident.) F Episode of mixed sharp and slow epileptic activity appearing spontaneously in sleep. (From an airline pilot who had a closed head injury two years previously and later had two major fits; abnormalities possibly unrelated to, or causative of injury.) 
the changes is in itself slight, eg, reduced fast, reduced alpha, and increased slow rhythms. Epileptic abnormalities can be provoked by drowsiness, as illustrated in Fig. 1F by the slow and sharp wave activity which appeared in an airline pilot.

\section{Sampling problems and special techniques}

When an abnormality is ordinarily intermittent, such as a burst of spike-and-waveactivity, repeated or prolonged records or both may be needed to demonstrate or 'exclude' it. It is desirable to have the relevant special patient conditions (eg, sleep or cessation of drug therapy) or special recording techniques (eg, sphenoidal, depth leads). Often, however, an opinion may have to be based on a single routine test, whereas certain other investigations, like radiography, may have the benefit of additional special procedures, such as angiography or air encephalography. Further, routine EEG results vary in time and are subject to sampling problems (cf, plain skull radiographs).
This variation is an advantage only when it is used to assess progress.

\section{Evoked cerebral responses}

Evoked responses to sensory stimulation provide an aspect of special interest.

During sleep, sounds produce non-specific slowwave responses of the $\mathrm{K}$-complex type; these are large, widespread, and readily visible in the raw trace as illustrated in Figure 1C. These involve non-specific systems and can be provoked by many different types of stimuli such as sounds, touch or light. Any sound might suffice but those with novelty or with some personal significance may be more effective. This indicates that the incoming information is being scrutinized in some way.

Specific responses are confined largely to cortical receiving areas for a particular sensory modality, such as the occipital areas for light stimuli and contralateral sylvian areas for peripheral nerve stimulation. Photic responses
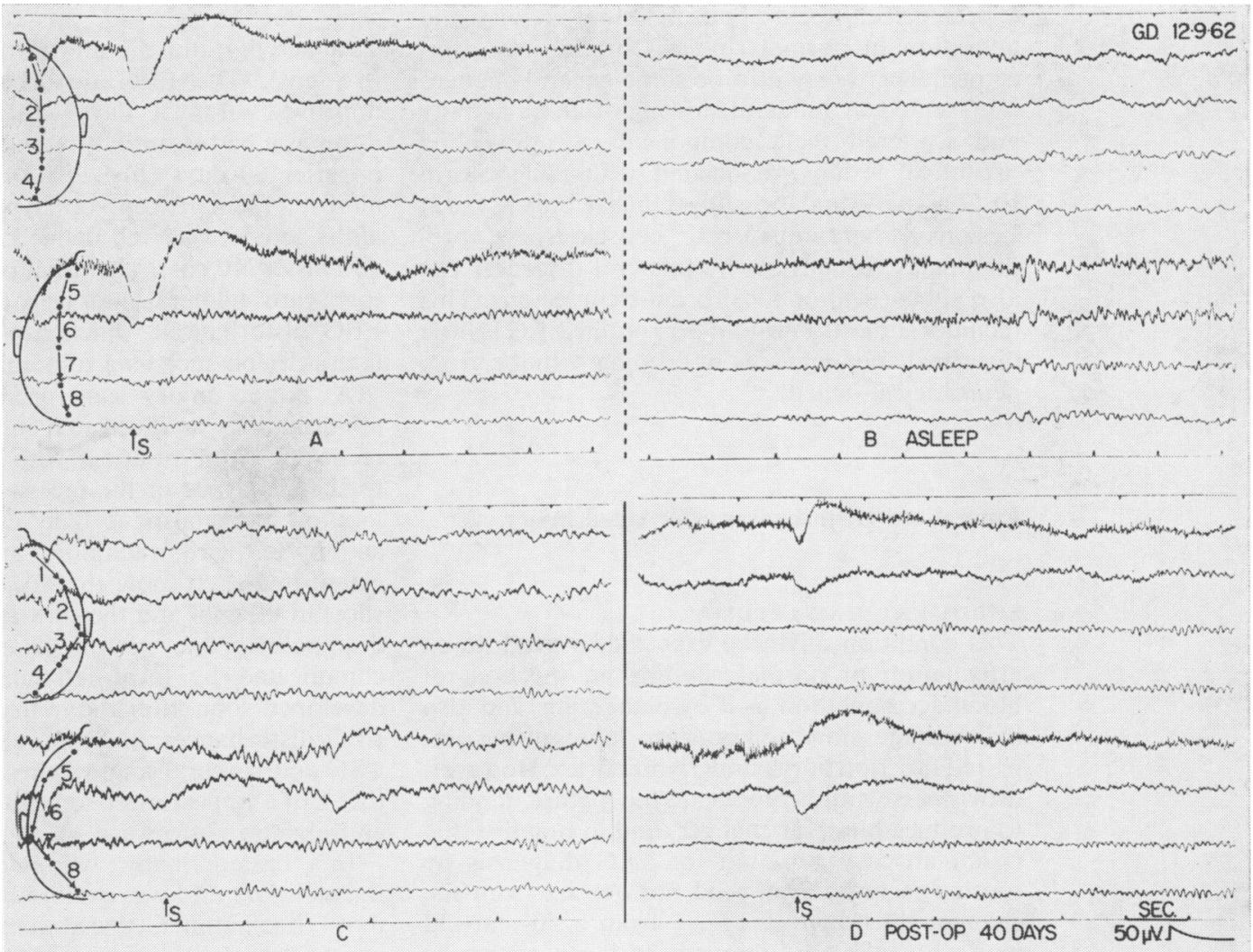

Fig. 2 Subdural haematoma (right sided) $A$ 57-year-old man who six weeks before suffered a minor head injury with transient loss of consciousness and developed headache and drowsiness.

A Waking Reduced alpha activity and increased slow components on the right in tracings from parasaggital areas. B Asleep More marked and extensive asymmetries in fast activity which is

reduced on the right where low voltage slow activity is persistent. C Awake Temporal derivations show bilateral theta range abnormalities with right emphasis, and relatively slow alpha activity (7-9 cps).

D Awake Forty days after operation, showing fairly symmetrical responsive alpha activity (10 cps) with little sign of previous slow activity and asymmetries. 
are usually fairly large and can be seen in the raw trace from scalp electrodes either as a response or as 'driving' (or 'following') of the ongoing rhythms. Peripheral nerve responses (somatosensory responses) are much smaller in scalp recording and require 'averaging', that is, the summation of many stimulations for their detection amidst the larger ongoing random EEG activity. Evoked response procedures are complementary to the study of spontaneous rhythms and may permit definition of particular types of defect in both neurological and functional terms.

\section{Traumatic EEG Disturbances}

For simplicity, the disorders may be divided into three general classes, although these are not exclusive. One patient may show predominantly one or other disturbance at different stages of the illness. The three classes are as follows. (1) Localized/lateralized disorder producing the expected local/focal abnormal slow activity and alteration in normal rhythms in the area concerned. There may also be some general changes represented by bilateral slowing of alpha activity and scattered theta components. (2) So-called 'irritative' lesions, associated with epileptiform EEG activity and possibly clinical epilepsy. (3) Lesions where disturbed consciousness predominates; usually severe/bilateral disorders but also subcortical or focal brain-stem lesions. This includes subjects in whom the routine EEG is little disturbed and seems out of keeping with the gross neurological deficit.

\section{Lateralized Disturbances after Head Injury}

\section{SUBDURAL HAEMATOMA}

This condition might be expected to produce an attenuation of normal rhythms in the area of blood accumulation as if by blanketing, and also low voltage slow components representing impaired function of the underlying cortex. However, drowsiness would complicate the picture, tending to produce bilateral changes, and in practice this is not an easy situation for EEG diagnosis by routine records. This need not detract from the changes illustrated in Fig. 2 from a 50-year-old man who suffered a minor head injury six weeks previously with transient loss of consciousness and then developed headache and drowsiness. Fast alpha range activity was less well seen on the right in the parasaggital $\mathbf{A} / \mathbf{P}$ derivations (Fig. $2 \mathrm{~A})$, and low voltage slow elements predominated in the same area. Such asymmetries were more obvious in light sleep (Fig. 2B), especially frontally and involved varied rhythms though slow activity remained more sustained on the right. Tracings from the temporal regions (Fig. 2C) showed mote bilateral disturbance, possibly because he wiss more drowsy. The appearances contrast co siderably with those in Fig. 2D from the posoperative record 40 days later when the patieft was more alert; alpha range rhythms appzared briskly and bilaterally on eye closure, and the was little slow activity.

\section{CEREBRAL CONTUSION}

Similarly cerebral contusion might be expected to cause reduced normal activity and increase्छु slow activity in the area affected, perhaps withogt the blanketing attenuation of the subdural haematoma, but possibly with the complicatien of post-concussion and contre-coup involvement. Some degree of bilateral disturbance is commont, as illustrated in Fig. 3 from a student who hadba right hemiplegia and aphasia following a carr accident six days before. Slow wave abnotmalities were prominent and alpha activity reduced on the left side in keeping with the clinim signs, but the right side was also involved in the slow activity and the alpha frequency was slow (6-8 cps). The EEG disturbances had greatty improved after 21 days when the paresis a d dysphasia had essentially recovered, and at folley up after 90 days (Fig. 3 A2) slow activity was almost absent (except on hyperventilation) a ad alpha activity was well defined, more symmetrie 1 and faster (10 cps). The usual problem is whether there are bilateral lesions or merely bilate 1 EEG disturbances, which can occur with a u lateral lesion such as a tumour.

A minor injury can produce considera舞 abnormalities as illustrated in Fig. 3B, an EEG recording from a patient who had a slight blis to the right side of the face without appreciate loss of consciousness. The EEG showed slow activity in the right temporal area and to a lessir extent in the left (note that the time constant was short at $0.1 \mathrm{sec}$ ) and the slow activity had largely disappeared one month later. The case complicated by focal left-sided seizures whith developed soon after the injury and some of the EEG disturbances might be related to these. Thie CSF and cerebral angiograms were normal, bett the EEG appearances on follow up were rogt entirely straightforward.

In a 'battered baby', who had a seizure following an injury and was explored for suspected sutbdural haematoma, there were prominent sleq wave abnormalities in the right temporal area (Fig. $3 C)$. Oedema was thought to be responsible. T⿳⺈ EEG appearances might have been aggravated $8 y$ the operation, and the predominance of slö rhythms in children has to be taken into accougt.

PENETRATING WAR WOUNDS These provide an important and attractiqe 


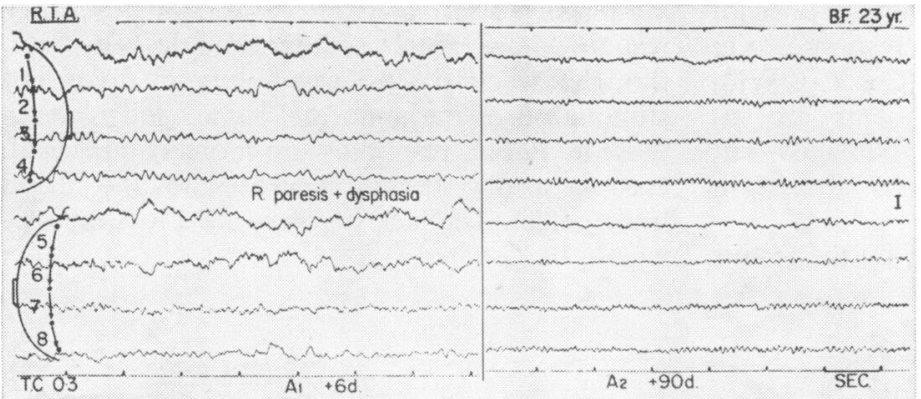

DOOR INJURY Al. $29 y$.
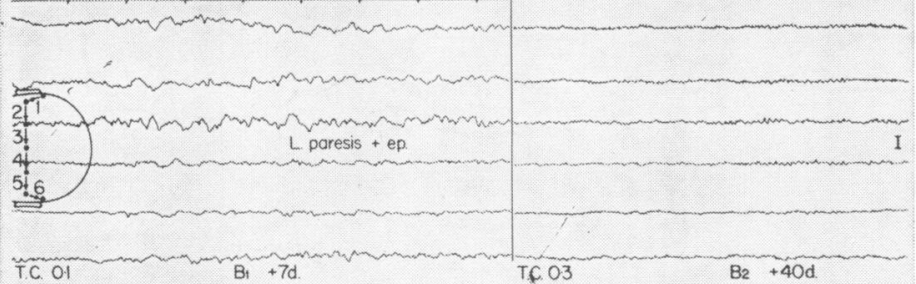

TC 03

$B_{2}+40 d$

BATTERED BABY MS 2 yr.
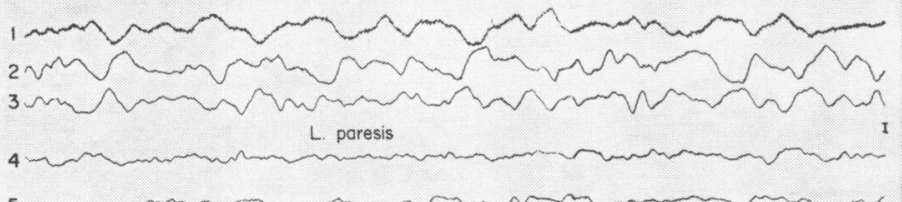

Fig. 3 Cerebral contusion A From a 23-year-old student in a car crash when possibly drunk; right scalp lacerations without fracture; unconscious 24 hours, and right paresis and dysphasia clearing largely within three weeks but with residual memory impairment and psychiatric complications. A1 At six days, slow activity maximal on the left, and slow alpha activity (6-8 cps) reduced on the left in keeping with clinical signs. A2 At 90 days slow activity almost absent and alpha activity more symmetrical and faster (10 cps).

B From a 29-year-old lorry driver who bumped into a door and sustained a trivial right scalp injury without loss of consciousness. A fit may have occurred five hours later, and focal motor attacks affecting the left face and hand developed five days later with slight left-sided weakness. B1 At seven days, widespread partly episodic slow activity affecting especially the right side (note time constant $0.1 \mathrm{sec}$ ). B2 At 40 days, disturbances have almost disappeared but some faster background asymmetries persist (increased amplitude on right). Slight facial weakness.

C 'Battered baby', aged 2 years, who was thrown on the floor and had a fit followed by a left hemiparesis. Angiogram indicated a shift to the left but exploration showed no substantial bleeding. EEG eight days following injury (five days after operation) shows extensive but mainly right-sided slow activity. Only mild left arm weakness one month later. opportunity for multidisciplinary study, especially since the opportunity should be unrepeatable. Unfortunately the classic war work by Denis Williams (1941a and b) does not yet have a long-term sequel here, unlike some American studies (Walker and Jablon, 1961). Such cases are complicated for electroencephalography because skull defects and calvarial plates may create unusual potential gradients which are difficult to interpret. It seems likely that loss of cortical function (eg, in fast activity) may be more than compensated for by a voltage increase due to a bony defect, and increased amplitudes of both normal and abnormal waveforms are often found in the wound area. Such findings are illustrated in Fig. 4A in a patient with a left parieto-temporal occipital wound causing speech, motor, and sensory defects and hemianopia. The waking record of this patient shows extensive ragged, mixed frequency slowwave abnormalities widely on the left side, and in sleep slow rhythms are again increased on the left both spontaneously and in response to a sound ( $\mathrm{K}$ complex). There is some reduction in normal alpha activity in comparison with the normal side but this is not prominent.

Such obvious disturbances may be largely lacking in the waking state. This is illustrated in the second subject with an extensive left frontoparietal wound causing speech, motor, and sensory defects. In Fig. 4C comparison of normal spontaneous awake rhythms is complicated by their relative absence, but when provoked by a flashing light they appear almost equally postcentrally. Note that the tracing speed is half that used in the previous case. There is some irregular low-voltage activity in the left fronto-sylvian area and it might be thought that the skull plate was minimizing abnormal activity; but in sleep the asymmetries are much more obvious, the voltage of spontaneous and sound-evoked activity being increased on the left. The relative lack of abnormal activity when awake might be due to an undercutting effect of the lesion in the second case, as opposed to the first. These findings illustrate the importance of the state of the patient and evoked activity, and the fact that different mechanisms may be involved for different types of activity. But this is going into too many uncertainties, though it is an aspect of particular interest. It is also of some importance in relation to open head injury, recurrence of tumours, and other conditions.

Evoked sensory responses are of special interest from the viewpoint of evoked response mechanisms in relation to clinical deficits and EEG findings. The types of result obtained are illustrated in Figure 4. In the first case (Fig. 4A and B) with somatosensory responses from stimulating the abnormal right hand, there is a fairly prominent contralateral (C3, T3) negativepositive wave (maximal at $75 \mathrm{msec}$ ). There is also a prominent ipsilateral response $(\mathrm{T} 4, \mathrm{C} 4)$, but 
when the intact left hand is stimulated (with subjectively equal stimuli) both responses are smaller, especially the ipsilateral (C3, T3). With photic stimulation, some components are increased in amplitude over the damaged left hemisphere $(\mathrm{O} 1, \mathrm{C} 3)$ and are also altered in apparent polarity and form.

In the second case (Fig. 4C and D) the results are displayed similarly. However, somatosensof. responses are much smaller and less distinction though the contra-ipsi asymmetry in favour stimulation of the abnormal right hand is aga present. Photic responses are more symmetricat even centrally, despite nearness to the plated bony defect. The lack of visual field loss is note worthy.

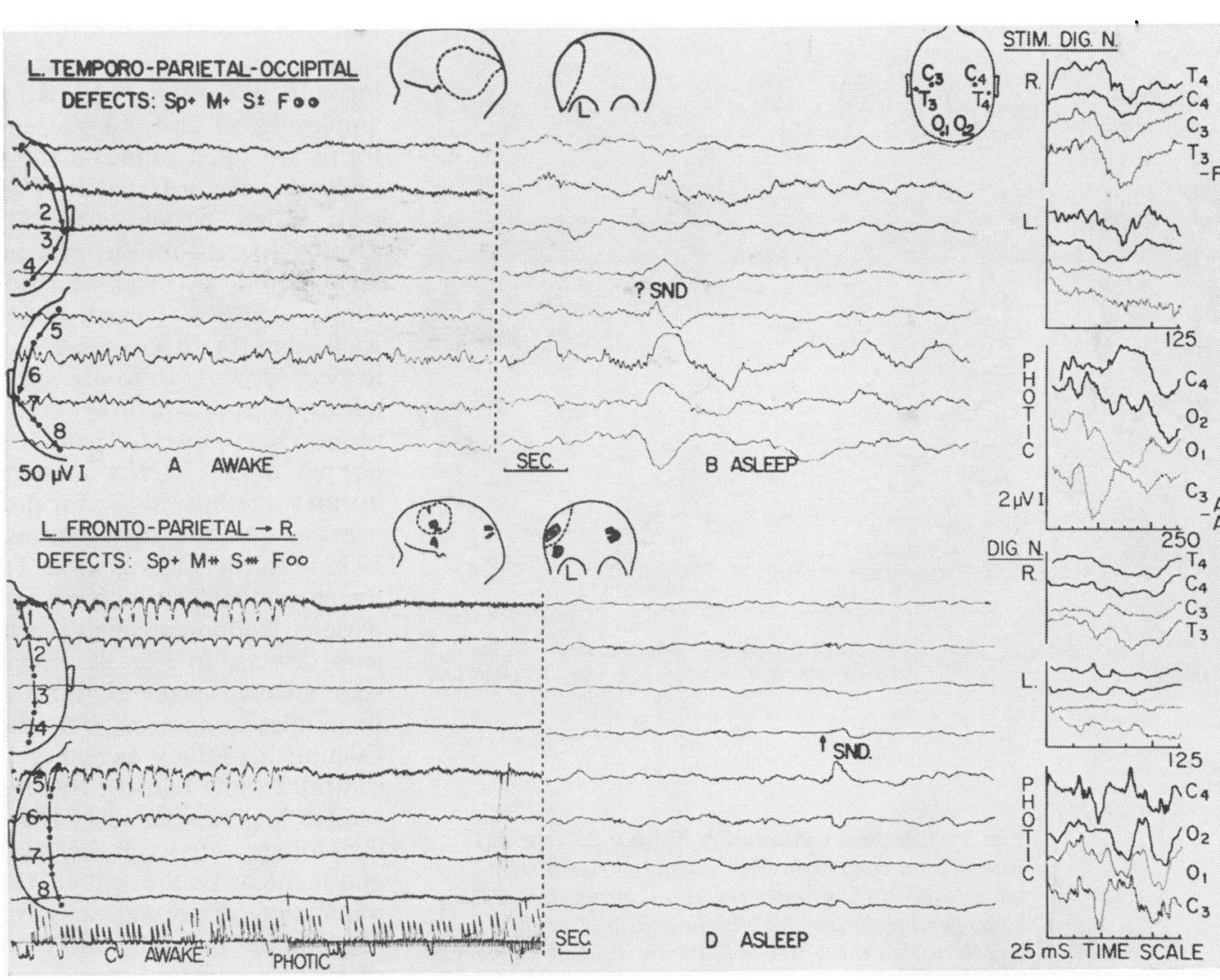

Fig. 4 Penetrating war wounds

$\mathrm{A}$ and $\mathrm{B}$ refer to a former soldier aged 45 years who sustained an extensive penetrating left parietotemporo-occipital grenade wound 25 years previously. He had slight residual speech, motor, and sensory defects and hemianopia; occasional major and focal sensory fits; no plate on the skull.

A Awake Extensive left-sided, mixed frequency slow wave abnormalities including sharply contoured recurring components B Asleep. Slow activity is increased, especially on the left, and the slow wave arousal response (K complex) is similarly asymmetrical.

Tracings $\mathrm{C}$ and $\mathrm{D}$ refer to an ex-Guardsman aged 49 years, who 26 years earlier sustained an extensive penetrating left frontal wound with fragments passing to the right posterior parietal region. He had considerable motor and sensory deficits and occasional seizures (major and possibly minor); calvarial plate was fitted. C Awake Little rhythmic activity on either side even though the eyes are closed, but there is more irregular slow activity on the left; during photic stimulation, 'following' responses appear bilaterally postcentrally (also frequency analysis display-channels 4 and 8). D Asleep Slow wave asymmetries are more obvious, and the soundinduced $K$ complex is also increased on the left. Note that the tracing speed is half that in $\mathrm{A}$ and $\mathrm{B}$. $\frac{\mathrm{T}}{\mathrm{O}}$ (Bony defects are shown by dashes.)

The averaged evoked cerebral responses appear on the right-hand side for the two cases; left-sided EEG derivations are shown by dotted line. Negative 0 deflection is upwards. Somatosensory responses arisew from electrical stimulation of digital nerves $(2-4 / \mathrm{sec})$ and photic responses from light flashes $(2 / \mathrm{sec})$. In the first case (A and B) stimulation of the abnormal right hand produces larger somatosensory responses of both ipsi- and contralateral than does stimulation of the normal left hand, at subjectively equal stimulatiog levels (averages of 512 stimuli). Photic responses show complex differences in amplitude and form (averages of 256 stimuli). In the second case $(\mathrm{C}$ and $\stackrel{\mathbb{Q}}{\stackrel{\mathbb{Q}}{2}}$ D) somatosensory responses are not well defined buto appear relatively greater when the abnormal hand is stimulated $(n=512$ stimuli). Photic responses are more nearly comparable on the two sides $(n=128$ stimuli). 
Evoked response studies have only recently begun; the results are complex, but the technique has to be encouraged because the results provide a way of tracking sensory mechanisms in the central nervous system and of comparing spontaneous and evoked activities which are themselves ill understood.

\section{INTERNAL 'TRAUMA'}

Demonstration of the patchy bilateral slow wave changes and low-voltage features attributed to repeated head trauma in boxers would complete this section and encourage those opposed to this form of elective trauma. However, the appearances are not specially interesting. As a contrast it is perhaps salutary to illustrate an example of 'medical trauma' due to angiography (Fig. 5). In a migrainous patient who had a left carotid angiogram, slow activity appeared widely and later gradually subsided. Asymmetries in photic driving response (15 fps) were present occipitotemporally but were not seen with the slower stimulus response $(1 / \mathrm{sec})$ on computer analysis (occipital). It may be that angiography merely irritated existing lesions and hastened some attack but no abnormality was seen on the angiogram and this was no ordinary attack.

\section{'Irritative' Lesions and Epileptiform Activity}

These disturbances are common in local lesions, both acute and chronic, and seem to reflect fairly accurately local cortical damage, including contre-coup lesions. Prediction of epileptic symptoms is of obvious importance. However, clinical attacks in any epileptic are only the exceptional and occasional event, and the problem
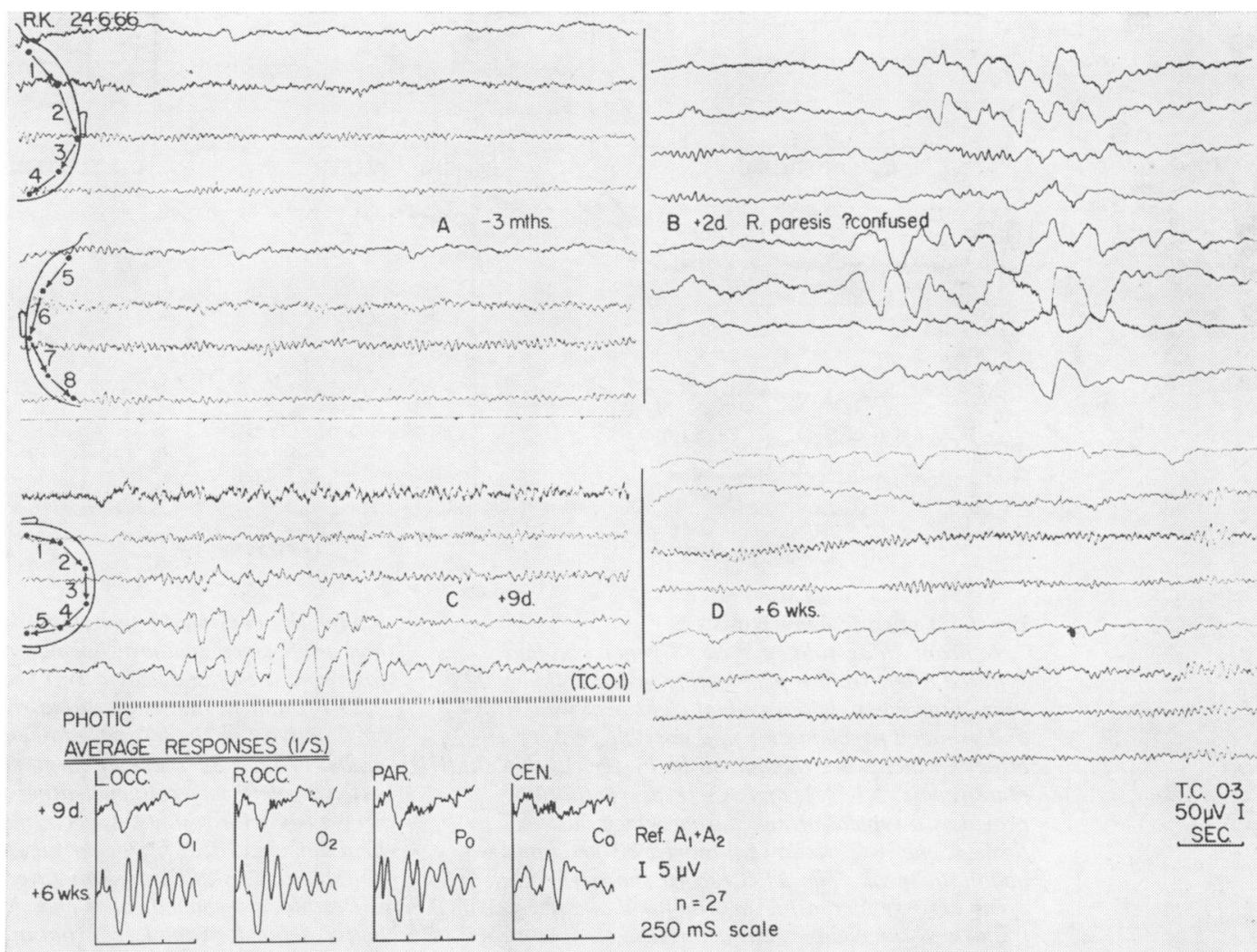

Fig. 5 Internal 'trauma'

A nurse, aged 25 years with an 18-month history of migraine, developed confusion and right-sided weakness and aphasia following left carotid angiography, which was normal. Symptoms gradually cleared during the next two weeks.

A Three months before angiography. Slight left temporal slow wave abnormalities. B Two days after angiography. Extensive partly episodic slowwave abnormalities with left-sided emphasis. C Nine

days after angiography. Left-sided slow activity still present, and asymmetrical photic driving responses at $15 \mathrm{fps}$. (Note time constant $0.1 \mathrm{sec}$.) D Six weeks after angiography. Result resembles the initial tracing.

Average photic-evoked responses appear at bottom left hand side; flash stimulation $(1 / \mathrm{sec})$ at nine days and six weeks after angiogram $(n=128)$. Responses are small and lack rhythmic content bilaterally at nine days, the differences possibly being due to changes in background activity content and level of consciousness. 
is what carries the EEG spike/sharp wave discharges into substantial activity to take over an appreciable area of cerebral function. Clinically it is thus not unexpected that there will be difficulties in predicting the clinical consequences of such inter-seizure or 'interictal' paroxysmal EEG abnormalities in any individual, since little is known of the controlling influences which presumably restrict the discharges to beifg mere EEG events; and these discharges need not be particularly significant just because they ate large, impressive or frequent in scalp recordings. Sampling problems, special patient conditions. and recording techniques are all clearly relevafif. Routine EEGs often merely indicate some pedisposition towards epilepsy, its locus of orig

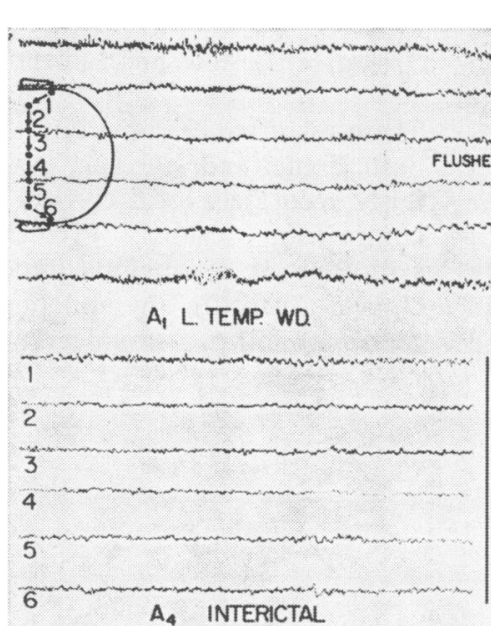

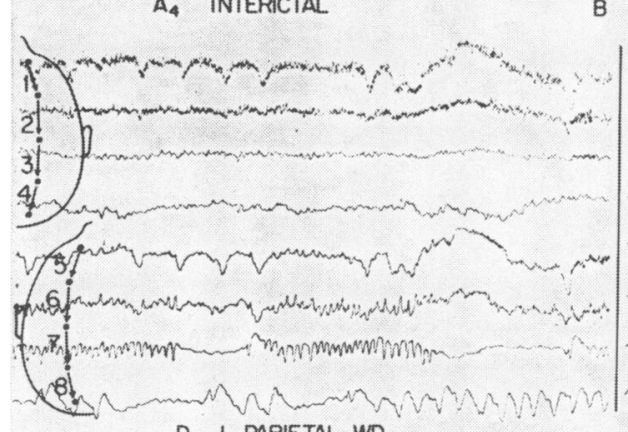

D L. PARIETAL WO.

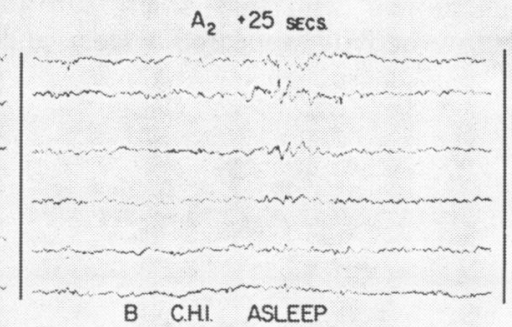

B C.HI ASLEEP
C LSUBOURAL
Fig. 6 Epileptic disturbances

A From an ex-soldier aged 48 years who had suffered a left frontal penetrating grenade injury 22 years previously, with residual right arm weakness and grouped psychomotor and possible sensory attacks which were thought to be hysterical. No skull plate repair. A1, A2, and A3 Hyperventilation provokes a typical attack during which patient flushed, chewed, swallowed, moved his head and was unable to speak. The EEG record shows rhythmic leftsided activity increasing in amplitude and decreasing in frequency, the changes outlasting the clinical attack. A4 EEG abnormalities between seizures (interictal) were infrequent and slight but distinctive; low voltage sharp and slow activity appears mainly in the left temporal area.

B More obvious runs of sharp activity during sleep in the right temporal area. (From a 41-year-old sailor with psychomotor epilepsy following minor head injury 20 years previously, without definite concussion or deficit but a fit occurred three days after injury.)

C Sustained left-sided mixed slow-wave abnormalities with rather sharp elements in a 50-year-old

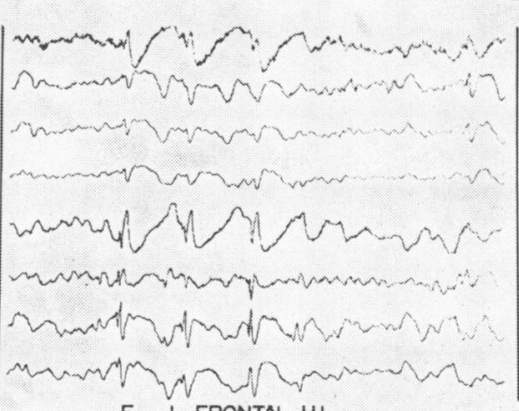

F L. FRONTAL H.I man with occasional psychomotor attacks. Patient had a left-sided subdural haematoma evacuated following a traffic accident two years previously.

D Prominent bursts of varied rhythmic sharp and $D$ slow activity in the left parieto-central and occipital 을. areas. From a 59-year-old ex-gunner who suffered an extensive left parietal penetrating wound 25 years of previously with residual speech, motor, sensory, and N field defects. Focal fits occurred eight years later but N్ not since. No skull plate was fitted.

E Prominent grouped spike and slow wave discharges better defined on the left. From a 24-year-old man who went over the handlebars of his bicycle nine years previously; he became briefly unconscious, sustained a left frontal fracture and subsequently had a dural repair for pneumocephalus. Major seizures appeared within two weeks and persisted though very infrequently despite the active EEG abnormality.

$\mathrm{F}$ Sharp and slow wave discharges with lid flickering and feelings of jumpiness provoked by photic stimulation (22 fps) plus eye closure. From a 19-yearf old motor cyclist who three weeks before had an un-음 explained road accident at night followed shortly afterwards by a convulsion. 
and likely clinical nature, whether there are changes in serial records with therapy, and whether some factors might be specially relevant such as sleep, hyperventilation, or photic stimulation.

The EEG changes in a psychomotor attack in a serviceman with a left frontal penetrating wound sustained 22 years previously are illustrated in Fig. 6A which shows rhythmic slow activity in the left temporal area, spreading and decreasing in frequency and then subsiding. This occurred regularly with hyperventilation, but is an exceptional occurrence in the EEG laboratory, unless activating procedures are used (eg, metrazole with ciné film studies). The interictal discharges in this patient (previously thought to be having hysterical attacks) were small but distinctive (Fig. 6 A4) and indicated the likely origin of and predisposition to attacks. Thus, even without the luxury of a recorded and witnessed attack, the diagnosis of post-traumatic left temporal epilepsy would seem more reasonable than hysterical attacks. Much greater changes would have been observed with special electrode placements (Bickford and Klass, 1966). Such interictal phenomena are often quite obvious, as shown in Figure 6B. This was a case of right temporal lobe epilepsy following a closed head injury, and sharp waves were much more prominent in sleep. Other abnormalities may clearly indicate continuing disorder, as shown in Fig. 6C from a patient with occasional psychomotor attacks two years after removal of a left subdural haematoma, but 'paroxysmal' aspects may be rather indefinite, many components appearing sharp. Thus the likely site of epileptic disorder is clear, but not its risk of occurrence, and routine EEG alone is not well suited to assess this at present (Marshall and Walker, 1961; Walker and Jablon, 1961; Jennett, 1962; Bickford and Klass, 1966).

Paucity of sharp waves from scalp recordings is disappointing in the proven epileptic, and so is an excess of discharges in subjects without definite clinical epilepsy. For instance in Fig. 6D, from a subject with a left parietal penetrating wound sustained 25 years ago, there are prominent runs of varied sharp and slow activity, but these were not associated with overt attacks though there had been seizures 17 years previously. Perhaps undercutting is responsible for this clinical result.

The question of bilateral involvement is a common problem. Figure $6 \mathrm{E}$ shows prominent bilateral runs of sharp and slow activity in a cyclist who had sustained a left frontal fracture and had had a dural repair for pneumocephalus nine years before; fits became a persistent disability but were only occasional despite a very abnormal electroencephalograph. There is a left-sided emphasis in the sharp/slow wave activity which may accurately represent the main area of injury, and the right-sided involvement is possibly a functional 'mirror focus' effect.
However, it may result from a contre-coup lesion. Clinically, a constant seizure pattern may indicate that the left side contains the epileptogenic focus. The development and persistence of left-sided EEG features over the years and during different states of consciousness may provide valuable support for this view, and special EEG studies could also help to clarify it (Bickford and Klass, 1966).

A not uncommon problem is the occurrence of an unexplained head injury possibly followed by a seizure under circumstances that make it uncertain whether the attack caused the injury or vice versa. Sensitivity to a flashing light can be a valuable pointer to the probable sequence of events. This is shown in Fig. $6 \mathrm{~F}$ from a patient who had an unexplained motor-cycle accident at night followed by a fit. This kind of sensitivity would be an otherwise exceptional development after a head injury and this strengthens the view that an epileptogenic tendency, possibly longstanding, was an important factor.

\section{Lesions with Disturbed Consciousness}

\section{COMA}

This occurs commonly with substantial acute brain damage (Loeb, 1958; Fischgold and Mathis, 1959; Cobb, 1963; Silverman, 1963). Also possible are local subcortical or brain-stem lesions which produce selective disturbances of consciousness and sleep mechanisms, or are associated with unusual clinical deficits without marked cortical dysfunction (Loeb, 1958; Loeb, Rosadini, and Poggio, 1959; Kaada, Harkmark, and Stokke, 1961; Chatrian, White, and Daly, 1963; Silverman, 1963; Chatrian, White, and Shaw, 1964; Bickford and Klass, 1966; Otomo, 1966). During recovery from coma there is usually a change from the large slow waves of the unresponsive state to the more normal alpha activity of the conscious state. The problem is whether the brain has been seriously altered by all this or is essentially normal, apart from factors causing the unconsciousness. Recovery is seen in Fig. 7A, but the slow activity initially is more prominent on the left where it tended to persist. Later it appeared as isolated recurring slow waves thereby favouring local left frontal damage. In contrast, the other patient with barbiturate poisoning, hypothermia, and complicating cardiac arrest progressed similarly from coma to reasonable recovery without particular focal EEG residua (Fig. 7B). It would not seem reasonable to diagnose gross cerebral damage from a state of functional impairment, and the difficulty in predicting permanent and important damage at an early stage is obvious.

The EEG tends to be disturbed in any confusional state. Figure 8 shows the record in a closed head injury patient whose behaviour 

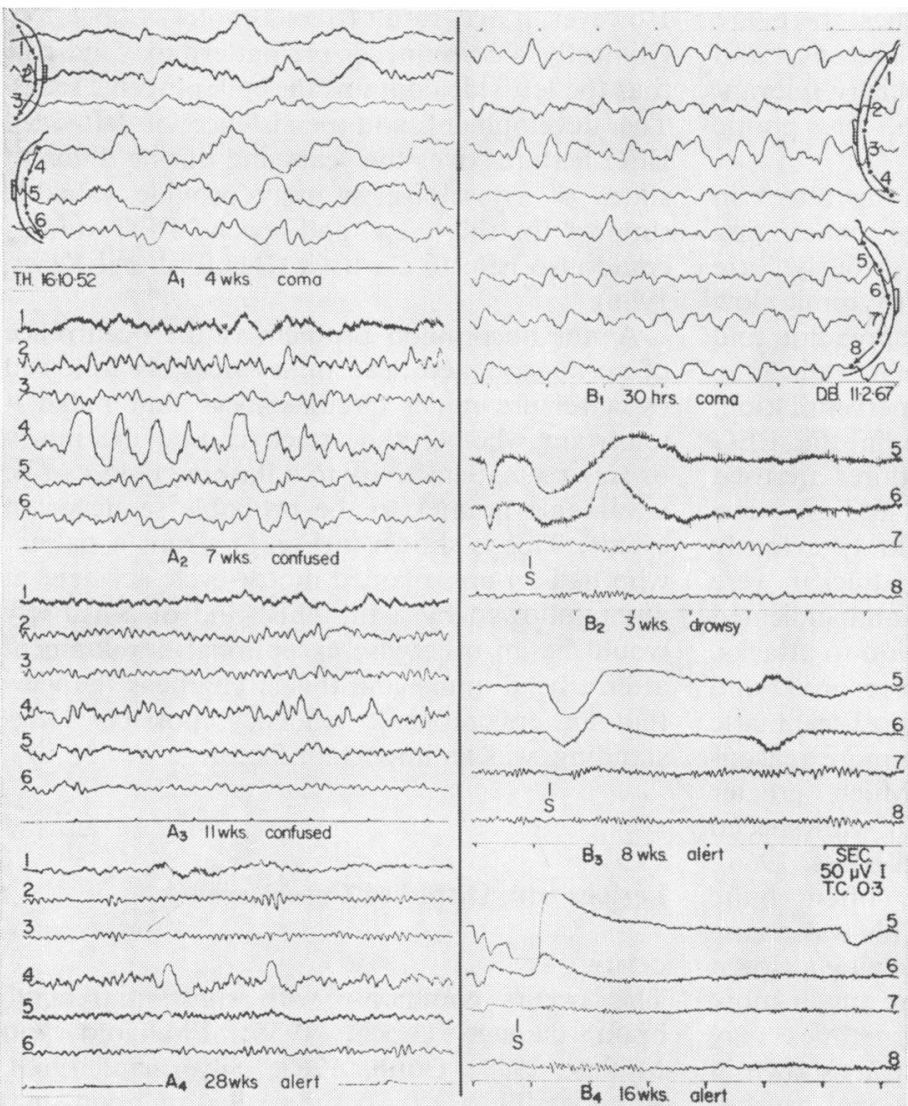

Fig. 7 (On the left) Recovery from coma

A Head injury $A$ 25-year-old motor cyclist who sustained a severe head injury and later became comatose with left extradural and right subdural haemorrhages; in coma for five weeks and then recovered fairly rapidly; primary optic atrophy a complication. A1-A4 EEGs at 4, 7, 11, and 28 week after head injury show decreasing slow activity with a return of alpha range components, increasing in frequency. Slow activity is maximal on left and persists thus frontally.

B Non-traumatic/metabolic A psychiatric patient, ڤ aged 42 years, comatose following pentothal, severe hypothermia, and cardiac arrest;

she made a satisfactory recovery. B1-B4 EEGs at 30 hours, 3, 8, and 16 weeks show varied slow activity while patient was comatose, followed by rapid progressive return of faster normal waking rhythms with clinical recovery.

Fig. 8 (Below) Bilateral abnormality with mental disturbance

Moderately severe closed head injury with fractureof right frontal area in a 20-year-old driver of a sports car (plus alcohol). Lethargic and drowsy for three weeks but sutisfactory recovery.

A Ten days after the accident when patient poorly cooperative, lethargic, and incontinent; EEG shows $\vec{\bullet}$ responsive high voltage slow activity with episodic features and ill-defined alpha range components.

B One year later. Only slight/moderate excess of slow components postcentrally, occasionally spreadin widely; alpha activity is now well defined.

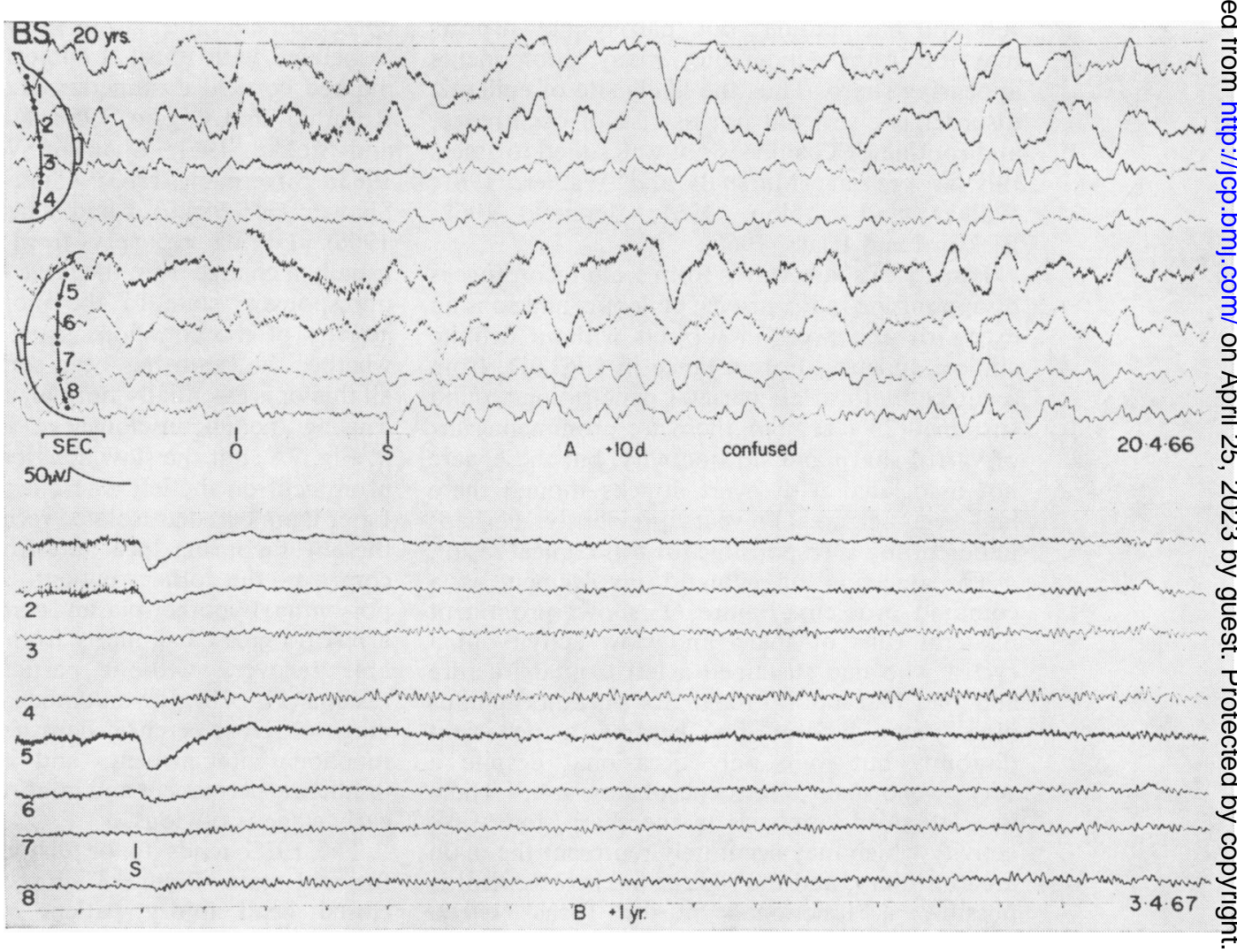


seemed much more disturbed than expected clinically. The EEG is quite abnormal, but whether due to the head injury per se or to metabolic complications is uncertain. This had largely resolved a year later. It is difficult to say whether multiple focal lesions (or a single subcortical lesion) or a metabolic functional upset should be sought for (Dow, Ulett, and Raaf, 1944). The latter may be hard to refute, and lesions can doubtless be found. It is noteworthy that alcohol, uraemia, hypoglycaemia, liver failure, or a recent fit may each produce something like this pattern, with recovery. In a patient who is brought in by the police, and may be drunk, epileptic, or suffering from a head injury, the alternative possibilities are at least thoughtprovoking.

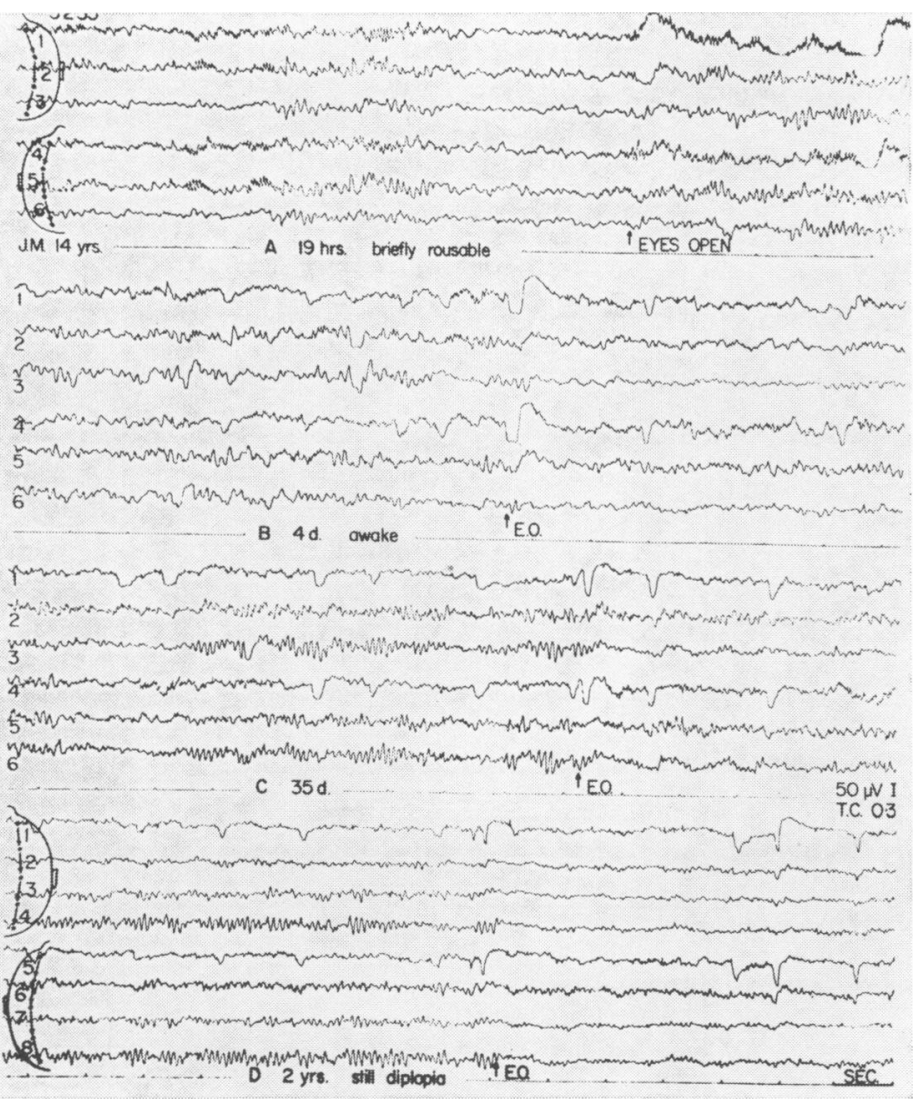

Fig. 9 Possible brain-stem contusion

From a 14-year-old boy injured heading a football; was dazed and later became drowsy, with ocular palsies and pyramidal signs; abnormalities recovered except diplopia (? also local ocular damage).

A At 19 hours when patient was briefly rousable. Mainly the changes of drowsiness, alpha range and slower activity appearing bilaterally on eye opening. B, C, and D Four days, 35 days, and two years later. Increasing alpha range activity and decreasing responsive slow components.
The EEG appearances in coma are not homogeneous or straightforward; a variety of patterns may be present suggesting varied mechanisms (Loeb, 1958; Fischgold and Mathis, 1959; Kaada et al, 1961; Chatrian et al, 1963; Silverman, 1963; Chatrian et al, 1964; Otomo, 1966), and the EEG findings may be difficult to relate to depth of coma and extent of damage. Suppression of activity can occur soon after injury, and be of grave significance if generalized and persistent (Dawson, Webster, and Gurdjian, 1951; Rodin, Whelan, Taylor, Tomita, Grisell, Thomas, and Gurdjian, 1965). An apparent discrepancy between clinical coma and EEG, such as low voltage near-normal rhythms or sleep states, may suggest brain stem involvement (Kaada et al, 1961; Chatrian et al, 1963; Silverman, 1963; Chatrian et al, 1964; Otomo, 1966). The findings in a suspected mid-brain contusion are shown in Figure 9. Initially the EEG shows changes in keeping with drowsiness, alpha activity coming back with a stimulus which alters the record from drowsiness to waking. There are also general slow wave disturbances which become more obvious with recovery and then gradually subside.

\section{WHITE MATTER LESIONS}

The lesions described by Strich (1956 and 1961) provide definite evidence of underlying pathology in the patient illustrated in Fig. 10-one of her original cases (Strich, 1956). This patient was well observed and took up the decerebrate posture from the time of the accident. The EEG within 15 hours of injury showed reasonable alpha activity, particularly when the patient was stimulated, but mixed slower and sleep rhythms predominated between times. The patient moved her leg and arm to painful stimuli but seemed otherwise unresponsive. Later records indicated some deterioration in background activity but a wakingsleeping distinction could be made and this was also observed clinically.

The relative lack of abnormality in the early stages, despite severe clinical disorder, contrasts with other lesions such as cerebral contusion, and can carry a poor prognosis. Such findings support the view that white matter lesions without cortical involvement may produce little disturbance of spontaneous EEG rhythms (apart from the effects of altered consciousness). It is noteworthy that this patient was considered clinically to be comatose at first and yet an EEG showed waking and sleeping states. It is in such cases of unusual coma and brain-stem lesions that polygraph and sensory stimulation studies may be specially interesting. These could clarify the depth and progress of coma, define sensory deficits, and assess the responsiveness of other systems such as motor and cardiorespiratory. These studies could include drug effects and improve our understanding of reticular activating mechanisms and such problems as concussion. 


\section{QUALITY OF SUR VIVAL}

The findings in two other situations are of interest. First is the assessment of 'functional' cerebral life, and second is the diagnosis of 'cerebral death'. The first is illustrated in Fig. 11 from a patient with a severe head injury which left him grossly impaired till death six years later, though he blinked to sounds and light, and may have obeyed commands. The EEG studies were limited and not very distinctive, as shown in Figure 11A. Alpha activity was poorly defined and slow activity more obvious on the left, and there were movement responses to sounds. The patient ground his teeth constantly at times (Fig. 11B), and it was possible to show that this was interrupted by calling his name, but not by a sound (whistle) on this occasion! Three years later, alpha activity was better defined on the right side (possibly not now postictal), and the tracing during sleep showe gross asymmetry, the left-sided potentials being severely reduced in spite of a skull defect (cf wolt wound). Evoked responses to sounds were also asymmetrical, and are shown in response to his. own and other names (Fig. 11 C3). Statistic measures and other polygraph studies would $\$$ necessary to determine the extent to which such information was 'understood', that is, dealt with relation to present and/or past experience. Electr\& encephalographic studies could also have beeg carried out systematically from the outset and greatly extended (Brit. med.J. leader, 1968; Poole, 1968) but this may not be worthwhile. However the reliable early prediction of such a dismal oug come might well have been valuable. Necrop showed gross destruction (and partial removal) of left frontal and temporal lobes, gross white matte

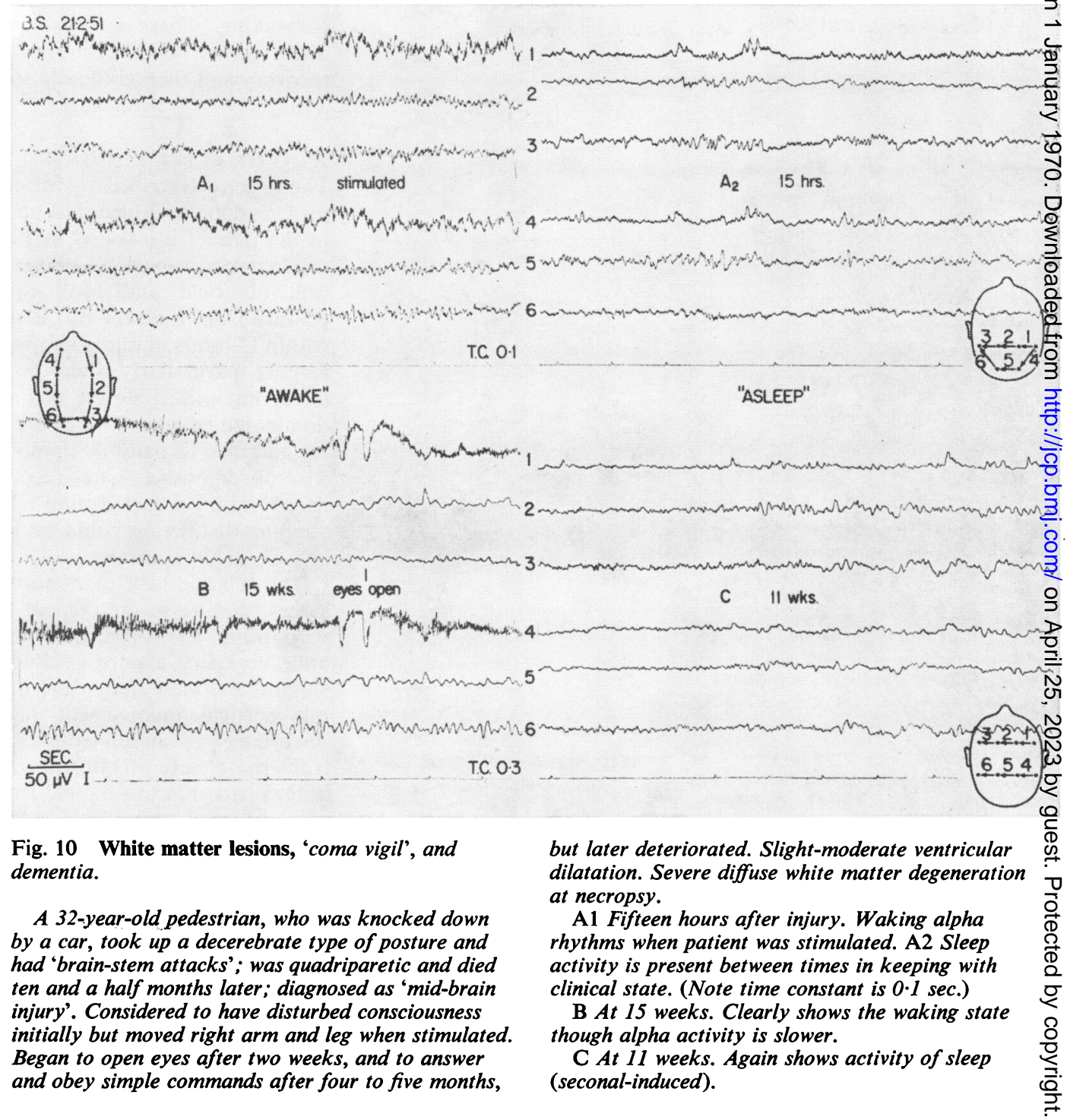


lesions in the right temporal lobe, and evidence of anoxia and infection (Dr Oppenheimer).

\section{'BRAIN DEATH'}

This is not just irreversible damage (which doubtless applies to much disease of the central nervous system) but is massive damage producing diffuse cerebral necrosis with irreversible coma beyond current therapy (Alderte, Jeri, Richardson, Sament, Schwab, and Young, 1968; Beecher, 1968; Brit. med. J. leader, 1968; Poole, 1968; Prior, 1969; Silverman, Saunders, Schwab, and Masland, 1969). This presents the structural versus functional problem in a new and important guise, so important that intoxications are excluded from proposed EEG criteria of irreversible coma and 'brain death' (Beecher, 1968; CIOMS Conference, 1968; Silverman et al, 1969). Records that are 'flat' in barbiturate poisoning represent

potential recovery of function, yet those after head injury do not, or may not. The patient referred to in Fig. 12A was comatose and mechanically ventilated following a head and neck injury, cardiac arrest, and anoxia. The record is by no means 'flat', there being muscle activity, unusual transients, and 'mess' (recording conditions are often dreadful). Responsiveness to stimuli is important (CIOMS Conference, 1968; Poole, 1969; Silverman et al, 1969) and the record during photic stimulation (Fig. 12 A2) shows no clear-cut distinctive EEG features. It would be unreasonable to attempt to satisfy anyone that this record contained no cerebral potentials. Necropsy showed total infarction of the brain including the brain stem (Dr Trevor Hughes). Figure 12B is a more acceptable 'flat' record from a patient with a severe head injury showing only EKG potentials even at high gain (kindly supplied by Dr Knight). Necropsy showed

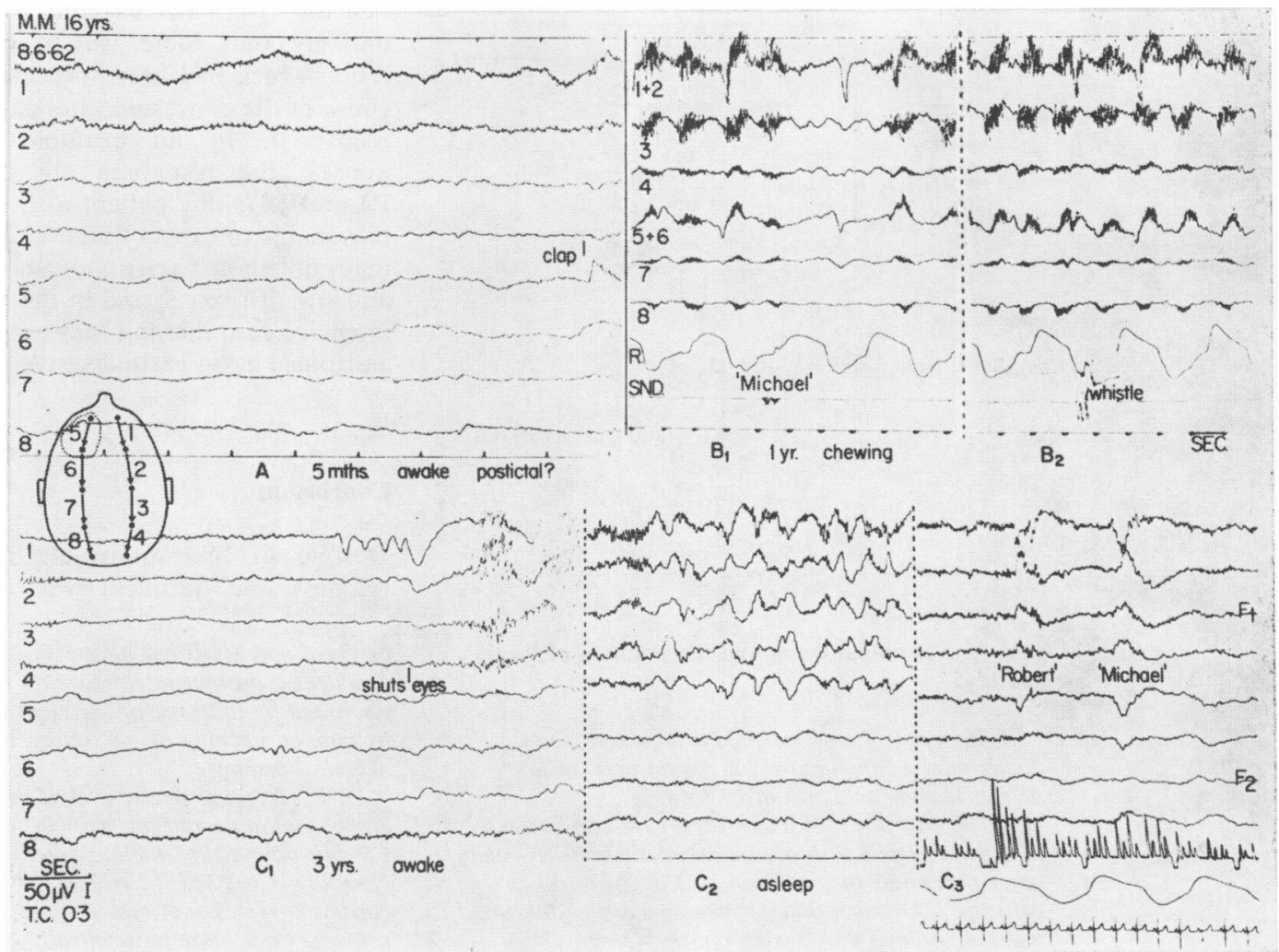

Fig. 11 Brain damage end-state and quality of survival

Severe traffic injury in a 16-year-old boy leading to a chronic 'vegetable' state, and death six years later. Left frontal compound fracture and later meningitis. At best, patient doubtfully obeyed simple commands and occasionally laughed.

A At six months. Scanty alpha range activity $(R>L)$ and increased left-sided slow activity. There is a movement in response to a clap; skull defect shown dotted. (Note?' postictal' record.)

B Polygraph during chewing episodes shows interruption of muscle activity when his name is called but not by a whistle.

C1 Awake at three years. Better defined alpha activity on the right, and increased slow activity on the left. C2 Asleep. Marked asymmetries of all sleep activity, reduced on left. C3 Asleep. Non-specific K complex responses to his own and family names, again asymmetrical. 
gross brain necrosis (Dr Sladden). In Figure 12C, from a patient in terminal coma following liver failure, there is a similarly flat record. Photic stimulation produced a prominent retinogram frontally without any occipital responses (Arfel, 1967; Poole, 1969; Poole, Chartres, and Wittrick, 1970). The retinogram was almost abolished by local masking and reduced by manual eye opening;

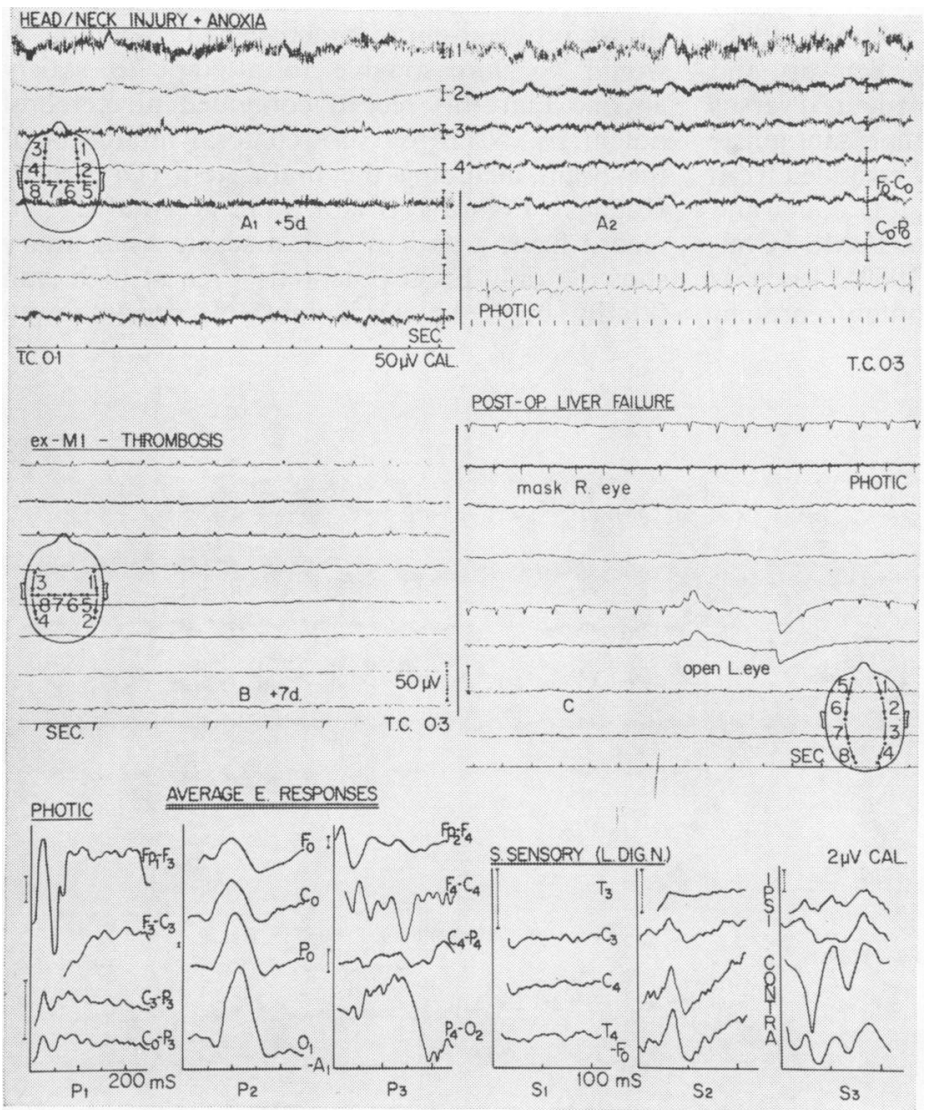

Fig. 12 Terminal coma and the problem of 'brain death'

A 45-year-old engineer had a head and neck diving injury complicated by anoxia and cardiac arrest, leading to death after 15 days.

A1 At five days, in an unresponsive state on a respirator; tracing shows muscle activity, EKG and other potentials of uncertain origin. (Note time constant is $0 \cdot 1 \mathrm{sec}$, difficult ward recording, elevated differing gains.) A2 During photic stimulation at 2 fps; no identifiable response. (Note gain and time constant alterations from A1.)

B A 40-year-old woman in a severe road traffic accident producing coma and death in seven days. At seven days, patient was comatose on respirator three hours before death. No definite cerebral potentials; specific stimulation procedures not available. (Note gain $3 \times$ normal.)

$\mathrm{C}$ Terminal coma in a 44-year-old woman with liver failure following halothane anaesthetics for limb fractures due to a road accident. No spontaneous this is not considered evidence of surviving cerebral function.

Cerebral evoked sensory response studies

It is in the setting of coma, severe cerebrail damage, and intensive care monitoring that are particularly interested in evoked sensogy response computer studies. These sensory response systems seem more resistant than spos taneous rhythms to insults and provide alternative check as to the presence of some types of surviving function (Poole, 1969; Poole et al, 1970). In the averaged results shown in Fig. 12 P for the first case A mentioned, photic stimulatiog produces little sign of a postcentral response though a frontal electroretinogram (Arfel, 1967 is obvious in channel Fp1-F3. With a high coid lesion there might well be no somatosensowy response to digital nerve stimulation-and there is little sign of one (Fig. 12 S1). In contrast, equally unresponsive, comatose, complex diabetie who had suffered cardiac arrest showed clear responses in both photic and somatosensory systems (Fig. 12 P2 and S2). This made unlikely that there was a massive mid-brağ lesion which had been suspected clinically as the cause of the coma and total paralysis; the patient recovered. In an example of postoperatiog anoxia, the responses are obvious (Fig. 12 P3 and S3); this patient also survived. It seems reasonable to expect that evoked response studies may contribute to our understanding of the natuge and site of lesions, and in the modern setting of intensive care therapy they may be of prognosiac assistance at an early decisive stage.

\section{Conclusion}

Despite its limitations, electroencephalograp remains one harmless way of assessing songe

cerebral potentials but photic stimulation (1 fps) produces a prominent retinogram frontally, almost abolished by masking of the right eye, and reduced $\frac{D}{O}$ by manual opening of the left eyelids; there is no occipital response.

P1-P3 Average photic evoked responses P1 Patient $A$, showing a prominent retinogram frontally (Fp1 N F3) but only a tiny dubious cerebral response post- N centrally (Co P3) (512 stimuli). P2 A complex diabet家, cardiac-arrest, coma case on a respirator. Photic responses are large postcentrally $(\mathrm{Po}, \mathrm{O} 1)$ commencing at $50 \mathrm{msec}$. (cp. calibration scales). Patient $\stackrel{\Phi}{\Phi}$ made an excellent recovery (256 stimuli). P3 Postoperative anoxic case showing large distinct specific responses ( $\mathrm{P} 4 \mathrm{O} 2)$; patient survived but with severe deficits (256 stimuli).

S1-S3 Averaged somatosensory responses followin $\frac{\vec{B}}{2}$ digital nerve stimulation. S1 Patient in $\mathrm{A}$; no responses (1024 stimuli). S2 Diabetic patient in $\mathrm{P} 2 ;$ distinct response in contralateral $(\mathrm{C} 4, \mathrm{~T} 4)$ derivationg commencing at 20 msec (256 stimuli). S3 Anoxic patient in $\mathrm{P} 3$; distinct responses (256 stimuli). 
aspects of normal and abnormal cerebral function in patients with head injury. Disappointment is inevitable at the lack of precision and incompleteness of these present studies; this is bound to happen with the clinical neurophysiologist who has to make do with everyday disasters rather than the niceties of animal experiments. And yet the deficiencies stem more from missed opportunities than from inherent inadequacy of technical skills or clinical complexity. There is little doubt that detailed EEG work, if deemed worthwhile in the medical economy, could improve assessments of the quality of surviving cerebral function and perhaps even provide reliable prognostic guidance at an early stage; and this must surely enrich ultimate pathological studies.

These studies were assisted by the MRC and come from the work of many EEG technicians and clinicians. I am particularly indebted to Miss M. Beauchamp and Miss F. Boselli for assistance in the selection and preparation of EEG material, and to Professor Ritchie Russell for the war brain wound cases.

\section{References}

Alderete, J. F., Jeri, F. R., Richardson, E. P., Jr., Sament, S., Schwab, R. S., and Young, R. R. (1968). Irreversible coma: a clinical electroencephalographic and neuropathological study. Trans. Amer. neurol. Ass., 93, 16-20.

Arfel, G. (1967). Stimulations visuelles et silence cérébral. Electroenceph. clin. Neurophysiol., 23, 172-175.

Harvard Medical School Committee (1968). A definition of irreversible coma. J. Amer. med. Ass., 205, 337-340.

Bickford, R. G., and Klass, D. W. (1966). Acute and chronic E.E.G. findings after head injury. In Head Injury Conference Proceedings, edited by W. F. Caveness and A. E. Walker, p. 63. Lippincott, Philadelphia.

British Medical Journal (1968). E.E.G. signs of death. (Leading article.) 2, 318.

Chatrian, G. E., White, L. E., Jr., and Daly, D. (1963). Electroencephalographic patterns resembling those of sleep in certain comatose states after injuries to the head. Electroenceph. clin. Neurophysiol., 15, 272-280.

Chatrian, G. E., White, L. E., Jr., and Shaw, Ch.-M. (1964). E.E.G. pattern resembling wakefulness in unresponsive decerebrate state following traumatic brain-stem infarct. Electroenceph. clin. Neurophysiol., 16, 285-289.

C.I.O.M.S. (1968). Round Table Conference on Heart Transplantation, p. 48.

Cobb, W. A. (1963). The E.E.G. of specific lesions. Head injury. In Electroencephalography, edited by D. Hill and G. Parr, pp. 332-339. Macdonald, London.

Dawson, R. E., Webster, J. E., and Gurdjian, E. S. (1951). Serial electroencephalography in acute head injuries. J. Neurosurg., 8, 613-630.

Dow, R. S., Ulett, G., and Raaf, J. (1944). Electroencephalographic studies immediately following head injury. Amer. J. Psychiat., 101, 174-183.

Fell, F. H., Gunning, A. J., Bardhan, K. D., and Triger, D. R. (1968). Severe hypothermia as a result of barbiturate overdose complicated by cardiac arrest. Lancet, 1, 392-397.

Fischgold, H., and Mathis, P. (1959). Obnubilations, comas et stupeurs. Electroenceph. clin. Neurophysiol., Suppl. 11.

Jennett, W. B. (1962). Epilepsy after Blunt Head Injuries, p. 121. Heinemann, London.

Kaada, B. R., Harkmark, W., and Stokke, O. (1961). Deep coma associated with desynchronization in E.E.G. Electroenceph. clin. Neurophysiol., 13, 785-789.

Loeb, C. (1958). Electroencephalographic changes during the state of coma. Electroenceph. clin. Neurophysiol., 10, 589-606.

Loeb, C., Rosadini, G., and Poggio, G. F. (1959). Electroencephalograms during coma. Neurology (Minneap.), 9, 610-618.

Marshall, C., and Walker, A. E. (1961). The value of electroencephalography in the prognostication and prognosis of post-traumatic epilepsy. Epilepsia (Amst.), 2, 138-143.

Otomo, E. (1966). Beta wave activity in the electroencephalogram in cases of coma due to acute brain-stem lesions. J. Neurol. Neurosurg. Psychiat., 29, 383-390.

Poole, E. (1968). E.E.G. signs of death. Brit. med. J., 3, 554.

Poole, E. W. (1969). Some aspects of evoked responses to stimulation in cerebral disaster. Electroenceph. clin. Neurophysiol., 27, 332.

Poole, E. W., Chartres, J., and Wittrick, E. K. (1970). Evoked cerebral sensory responses in the assessment of surviving function in cerebral disaster. Electroenceph. clin. Neurophysiol., 29, 105.

Prior, P. F. (1969). E.E.G. findings in dying and resuscitated adult patients. Electroenceph. clin. Neurophysiol., 27, 333.

Rodin, E., Whelan, J., Taylor, T., Tomita, T., Grisell, J., Thomas, L. M., and Gurdjian, E. S. (1965). The electroencephalogram in acute fatal head injuries. J. Neurosurg., 23, 329-337.

Silverman D. (1963). Retrospective Study of the E.E.G. in coma. Electroenceph. clin. Neurophysiol., 15, 486-503.

Silverman, D., Saunders, M. G., Schwab, R. S., and Masland, R. L. (1969). Cerebral death and the electroencephalogram. J. Amer. med. Ass., 209, 1505-1510.

Strich, S. (1956). Diffuse degeneration of the cerebral white matter in severe dementia following head injury. J. Neurol. Neurosurg. Psychiat., 19, 163-185.

Strich, S. (1961). Shearing of nerve fibres as a cause of brain damage due to head injury. Lancet, 2, 443-448.

Williams, D. (1941a). The electroencephalogram in acute head injuries. J. Neurol. Psychiat., 4, 107-130.

Williams, D. (1941 b). The E.E.G. in chronic post-traumatic states. J. Neurol. Psychiat., 4, 131-146.

Walker, A. E., and Jablon, S. (1961). A Follow-up Study of Head Wounds in World War II, p. 77 (VA Medical Monographs, 5) U.S. Govt. Ptg Off., Washington, D.C. 